\title{
Alcohol stress response dampening: Selective reduction of anxiety in the face of uncertain threat
}

\author{
K. R. Hefner and J. J. Curtin \\ Department of Psychology, University of Wisconsin-Madison
}

\begin{abstract}
Problematic alcohol use and stress-response dampening (SRD) are intimately interconnected. Recent evidence suggests that alcohol produces selective SRD during uncertain but not certain threat. We systematically varied shock probability in a novel task assessing alcohol SRD during low probable/uncertain threat, while holding temporal precision of threat constant. Intoxicated ( $0.08 \%$ target blood alcohol concentration) and placebo participants completed a cued shock threat task in which probability of shock administration at the offset of brief visual cues varied parametrically. High probability (100\%) shock cues represented certain threat as used in earlier research, while lower probability $(20 \% \& 60 \%)$ shock cues provided novel uncertain threat conditions. Startle potentiation during cues and inter-trial-intervals (ITIs) served as the measure of affective response. General linear model analysis indicated that alcohol SRD magnitude increased monotonically as threat uncertainty increased. Alcohol SRD was significantly greater during $20 \%$ and $60 \%$ shock threat relative to $100 \%$ shock threat. Alcohol also significantly reduced startle potentiation during distal threat in shock-free ITIs. Alcohol SRD magnitude during distal/ uncertain threat was meaningfully moderated by individual differences in negative affectivity and weekly alcohol consumption. This work advances understanding of which properties of uncertainty are relevant to anxiety and anxiolytic effects of alcohol.
\end{abstract}

\section{Keywords}

alcohol; stress response dampening; fear; anxiety; uncertainty; startle potentiation

\section{Introduction}

\begin{abstract}
Stress-response dampening (SRD), or the notion that alcohol consumption reduces one's emotional and physiological response to stressors, is intimately interconnected to alcohol use and alcoholism (Sher, 1987). Individuals hold an expectation that consuming alcohol reduces stress, which in turn motivates alcohol use (Cooper et al. 1995; Goldman et al. 1987). Drinkers reporting SRD as their dominant motive for use display increased risk for problematic alcohol use (Cooper et al. 1995; Schroder \& Perrine 2007). Furthermore, patients with anxiety disorders exhibit high rates of alcohol use, abuse, and dependence (Grant et al. 2004; Kessler et al. 1995). Furthermore, stress instigates relapse among abstinent alcoholics (Brown et al., 1990; 1995), and stress-induced reinstatement of use has been confirmed in animal models (Lê et al. 1998; Overstreet et al. 2007). Alcohol- and other
\end{abstract}

Corresponding Author: John J. Curtin, Department of Psychology, University of Wisconsin, 1202 West Johnson St, Madison, WI 53706, jjcurtin@wiscc.edu.

\section{Disclosure/Conflicts of Interest}

The authors declare that, except for income received from my primary employer and grant support from NIAAA (R01 AA15384), no financial support or compensation has been received from any individual or corporate entity over the past three years for research or professional service and there are no personal financial holdings that could be perceived as constituting a potential conflict of interest. 
drug-induced stress neuroadaptations figure prominently in addiction etiology (Breese et al., 2010; Koob \& Volkow 2010; Weiss et al. 2001). Consequently, research on alcohol-stress connections can identify pre-morbid risk factors, clarify etiologic mechanisms, and aid behavioral and pharmacologic treatment development for alcoholism. However, alcohol's impact on affective response to stressors, and the processes and neurobiological mechanisms mediating alcohol SRD, are still not well understood (Curtin \& Lang, 2007).

Progress clarifying alcohol SRD in humans has been slowed by the use of complicated tasks that do not allow sufficient precision and control to isolate specific mechanisms. Furthermore, substantial research has invoked affective measures that are too indirect to implicate neurobiological mechanisms (e.g., self-report) and/or those influenced by numerous non-affective processes, complicating interpretation (e.g., heart rate). In contrast, affective neuroscientists have made considerable progress explicating psychological and neurobiological mechanisms involved in affective response to stressors using cued threat of electric shock (Davis et al., 2010; Delgado et al., 2006; LeDoux, 1998; Phelps, 2006).

Specifically, programmatic research that measures startle reflex potentiation during cues that were contingently paired with shock ( $100 \%$ cue-contingent shock) has provided clear evidence that the central nucleus of the amygdala $(\mathrm{CeA})$ mediates defensive system activity during unambiguous, high probable, imminent threat (Davis, 2006). Systematic measurement of startle potentiation during $100 \%$ cue-contingent shock in rodents, nonhuman primates, and humans has provided an important animal-human translational bridge to study fear responding (Davis et al., 2008).

Additional manipulations that potentiate startle have been identified. Bright light, temporally uncertain shock, and infusions of the anxiogenic peptide corticotropin-releasing factor (CRF) potentiate startle response in rats (Liang et al., 1992; Swerdlow et al., 1986; Walker $\&$ Davis, 1997). In humans, darkness and unpredictable/non-contingent shock have been shown to potentiate startle response (Grillon et al., 1997, 2004). These threats are more ambiguous or otherwise uncertain relative to $100 \%$ cue-contingent shock; such uncertain threats produce more sustained rather than phasic startle potentiation in both humans and animals. Basic neuroscience research in animals indicates that CRF and norepinephrine (NE) sensitive pathways through the lateral division of the bed nucleus of the stria terminalis (BNST) appear to be responsible for observed increases in startle potentiation to uncertain threats (Walker \& Davis, 2008; Davis et al., 2010). Indeed, affective neuroscientists suggest that paradigms assessing startle response to uncertain threat provide valuable laboratory models in which to study anxiety (Davis et al., 2010; Grillon, 2008; Walker et al., 2003).

Previous work in our lab indicates that alcohol does not appear to reduce startle potentiation during well-defined, unambiguous, attentionally focal cues predicting shock (Curtin et al., 1998; 2001; Moberg \& Curtin, 2009). However, we have manipulated threat uncertainty to demonstrate that alcohol selectively reduced startle potentiation during uncertain threat (Moberg \& Curtin, 2009). Specifically, alcohol did not reduce startle potentiation when shocks were administered predictably ( $100 \%$ cue-shock pairing contingency) during brief visual cues. In contrast, alcohol robustly reduced startle potentiation when shocks were administered unpredictably (non-cue contingent shocks during cues and intervals between cues).

This previous research has provided intriguing preliminary evidence that alcohol may selectively dampen anxiety during uncertain threat but not fear during certain, imminent threat (Moberg \& Curtin, 2009). However, improved understanding of the precise nature and boundaries of this effect, along with its underlying neurobiological mechanisms, is warranted. In particular, our previous manipulation of shock threat uncertainty confounded the probability of shock with threat imminence by varying both the probability and the 
temporal presentation of shock threat, leaving crucial questions as to which stimulus characteristics are central to both the elicitation of anxiety and the anxiolytic effects of alcohol unanswered (Moberg \& Curtin, 2009). Shock was highly probable (100\%) and imminent (4.5s after cue onset) during cues in predictable blocks. In contrast, in unpredictable blocks, the probability of shock at any moment was low (and unknown). Furthermore, substantial temporal uncertainty regarding shock existed during these unpredictable blocks. To further disentangle the two characteristics of probability and temporal presentation of shock, we developed a novel paradigm to parametrically vary shock probability, while holding the temporal presentation of shock constant.

In this report, we describe a novel task that parametrically manipulated shock probability ( $20 \%$ vs. $60 \%$ vs. $100 \%$ ) during brief visual threat cues. Threat imminence was held constant during cues by administering all shocks at cue offset. We predicted that alcohol's SRD effect as measured by startle potentiation would increase with rising threat uncertainty (i.e., decreasing shock probability). We also examined alcohol's effect on startle potentiation during the variable duration, shock-free intervals between cues to test for SRD during periods of temporally distal (non-imminent) threat. Finally, we tested SRD-relevant individual difference moderators in trait affectivity, alcohol use, and alcohol problems.

\section{Materials and Methods}

\section{Participants}

A total of 120 (59 women) participants were recruited from the University of WisconsinMadison community via campus flyers and online advertisements. Preliminary study eligibility was assessed during a phone screening session. Participants were required to be at least 21 years of age and to report recent experience (within the last year) with the dose of alcohol to be administered in the study (i.e., 3 drinks in one episode for males, 2 for females). Potential participants were excluded if they reported a history of alcohol-related problems or a medical condition for which alcohol use was contraindicated. Participants who met these criteria were scheduled for an experimental session and told to abstain from alcohol and other drug use for 24 hours, and all food and beverages other than water for four hours, prior to their experimental session. All participants were compensated $\$ 15 /$ hour for their time.

\section{General Procedure}

Consent and Screening-On arrival at the lab, participants provided proof of age and signed a consent form approved by the University of Wisconsin-Madison IRB. All participants completed a medical screening questionnaire to verify their health status. Female participants were administered an in-stream urine pregnancy test (Northwest Andrology \& Cryobank, Inc., Spokane, WA), with a negative result required for participation. A pre-experiment blood alcohol concentration (BAC) of $0.00 \%$ was verified via breathalyzer (Alcosensor IV; Intoximeters Inc., St. Louis, MO). Participants were first informed about the electric shock administration during the consent procedure and were offered an opportunity to ask questions about it at this time. One participant elected to discontinue the experiment after description of the shock procedure, but prior to being assigned to a beverage group. A second participant who was assigned to the placebo group discontinued the experiment due to the acoustic probes used to measure startle response. Both participants were replaced.

Baseline Startle Response Assessment-Prior to beverage group assignment, participants completed a brief procedure to assess their startle response magnitude during a neutral baseline procedure. Participants viewed a series of eight colored squares presented 
on a CRT monitor. Each square was presented for $5 \mathrm{~s}$ with a variable duration inter-trial interval (ITI; range $=15-20 \mathrm{~s}$ ). Mean baseline startle response was calculated to 10 startleeliciting acoustic probes presented during cue and ITI periods in this baseline procedure (see Startle Potentiation Measurement section below). Mean baseline startle response was used as a covariate in all analyses of startle potentiation from the main task to increase statistical power.

Beverage Group Manipulation-Approximately equal numbers of male and female participants were randomly assigned to the alcohol and placebo beverage groups. All participants, regardless of beverage group assignment, were informed that they had been assigned to the alcohol group and would receive a moderately intoxicating dose of alcohol equivalent to 2-3 drinks in $1 \mathrm{hr}$ for a 160-lb person. Participants assigned to the alcohol group received beverages consisting of fruit juice mixed with 100 proof vodka (Smirnoff Blue Label) in a 3:1 juice to vodka ratio. The alcohol dose was calculated based on each participant's height, weight, age, and gender, to produce a peak BAC of $0.08 \%$ approximately 30 minutes after completion of beverage consumption (see Curtin \& Fairchild, 2003 for details regarding the dosing formula). Participants assigned to the placebo group received volume-matched beverages consisting of fruit juice mixed with water poured from a vodka bottle in their presence. Outside of their view, the drinks were misted with alcohol and two mls of alcohol were floated on top of the beverages to provide sensory stimuli to support the placebo manipulation. The total beverage was evenly divided into two drinks, each consumed in 15 minutes, for a total drinking period of 30 minutes. The main procedure began after a 15 minute post-drinking absorption period. Participants' BACs were measured at two points during the experiment: just prior to the start of the main procedure, and immediately following the completion of the main procedure.

Shock tolerance threshold assessment-Following the beverage group manipulation, participants reported their subjective response to a series of ordinally increasing intensity electric shocks ranging from just perceptible to $7 \mathrm{~mA}$, of $200 \mathrm{~ms}$ duration, to assess their maximum tolerance threshold per standardized procedures in our laboratory (e.g., Curtin et al., 2001; Hogle \& Curtin, 2006; Hogle, Kaye, \& Curtin, 2010; Moberg \& Curtin, 2009). Shocks were administered across the distal phalanges of the index and ring fingers of left hand. Shock intensity during the main procedure was set to each participant's subjective maximum tolerance threshold to minimize individual differences in sensitivity and possible analgesic effects associated with alcohol.

Main Procedure-Participants viewed a series of colored square cues presented for $5 \mathrm{~s}$ each, separated by a variable duration ITI (range $=15-20 \mathrm{~s}$ ) on a 21 inch CRT monitor positioned approximately $1.5 \mathrm{~m}$ in front of the participant. Cues were blocked into three Threat Probability conditions. In $100 \%$ threat probability blocks, participants were instructed that electric shocks would be administered during every cue presentation. In $60 \%$ threat probability blocks, participants were instructed that shocks would be administered on approximately 3 out of every 5 cue presentations. In $20 \%$ threat probability blocks, participants were instructed that shocks would be administered on approximately 1 out of every 5 cue presentations. These instructions accurately represented the probabilities of threat presentation in each block, and $200 \mathrm{~ms}$ duration shocks were administered at $4.5 \mathrm{~s}$ post cue onset. Participants completed two blocks (15 cues total) at each threat probability. Two neutral blocks of no-shock cues (15 cues total) were also completed to facilitate calculation of startle potentiation associated with shock threat (see Startle Potentiation Measurement section below). Participants were instructed that shocks would never be administered during no-shock blocks, and were informed (via text on monitor) of the upcoming block type. Block type was labeled throughout the block in the upper left corner 
of the monitor and different color cues were used for each block type to reinforce salience of threat probability condition. Participants were briefly questioned following procedure instructions to confirm that they understood shock contingencies for each block type. The block presentation order was fully counterbalanced across six between-subject orders. This procedure required approximately 22.5 minutes to complete (See Figure 1 for experimental design schematic).

Individual difference measures, debriefing, and release-After completing the main procedure, participants answered three questions to evaluate the success of our placebo manipulation. Specifically, (1) they estimated the alcohol content they had consumed, quantified as standard alcoholic drinks; (2) they reported their perceived level of intoxication on a five-point scale (scale range of $0-4$ with anchors of "not at all intoxicated" and "extremely intoxicated"), and (3) they estimated their peak BAC during the main procedure. Following this, participants provided information on their drinking history (current weekly frequency and quantity of alcohol use), history of problems related to alcohol use (Young Adult Alcohol Problems Screening Test; Hurlbut \& Sher, 1992, Short Michigan Alcohol Screening Test; Selzer, Vinokur, \& van Rooijen, 1975), and filled out a personality assessment measuring trait affectivity (Brief Multidimensional Personality Questionnaire; Patrick, Curtin \& Tellegen, 2002). Scores for all measures were calculated according to published guidelines.

After completing questionnaire measures, placebo participants were debriefed, paid and dismissed. Participants who had received alcohol remained at the study site until their BAC reached $.02 \%$, at which point they were debriefed, paid and dismissed.

\section{Startle Potentiation Measurement}

The eyeblink startle response was elicited by acoustic probes $(50 \mathrm{~ms}, 102 \mathrm{~dB}$ white noise with near instantaneous rise time) and measured by recording electromyographic activity in the orbicularis oculi muscle using $\mathrm{Ag}-\mathrm{AgCl}$ sensors placed according to published guidelines (Blumenthal et al., 2005). Eight acoustic probes were presented during both cues (4 s post-cue onset) and ITI periods between cues (at 13 or $15 \mathrm{~s}$ post-cue offset) in each block type (64 acoustic probes total). Serial position of the probes was counterbalanced within-subjects and a minimum of $13 \mathrm{~s}$ separated each probe from any previous startle eliciting event (e.g. another probe, electric shock). Startle eyeblink electromyographic activity was sampled $(2000 \mathrm{~Hz})$ and filtered $(30-500 \mathrm{~Hz})$. Offline processing included signal rectification and smoothing ( $30 \mathrm{~Hz}$ low-pass). Peak eyeblink response between 20-120 ms post-probe onset was scored relative to mean $50 \mathrm{~ms}$ pre-probe baseline. Startle potentiation was calculated separately for cue and ITI periods in each of the three threat probability block relative to the matched period in the no-shock block.

\section{Data analytic strategy}

Data analysis and figure preparation were accomplished within R (R Development Core Team, 2009, Tinn-R Development team, 2004). All analyses were accomplished within the General Linear Models. Primary analysis of startle potentiation included repeated measures for Threat Probability (100\% vs. $60 \%$ vs. $20 \%$ ) and between subject regressors for Beverage Group, Block Order, and Baseline Startle. Moderation analyses added quantitative regressors for relevant individual difference measures. 


\section{Results}

\section{Sample Characteristics}

The sample included 59 women and 61 men. The mean age of the sample was 22.2 years ( $\mathrm{SD}=2.3$ years, Range: $21-35$ years). Participants self-reported an average of 2.0 drinking episodes per week ( $\mathrm{SD}=1.5$ episodes, Range $=0.25-10.5$ episodes) and typically consumed 4.4 standard alcoholic drinks per episode ( $\mathrm{SD}=2.3$ drinks; Range $=1-13$ drinks). Participants reported a mean of 0.7 lifetime problems $(\mathrm{SD}=1.0$; Range $=0-4)$ on the 13 item Short Michigan Alcohol Screening Test. They reported experiencing a mean of 5.4 alcohol-related consequences in the past year $(S D=3.0$, Range $=0-14)$ on the Young Adult Alcohol Problems scale, which measures consequences of varying severity (e.g., late to or missed class/work, fight with boyfriend/girlfriend) associated with their alcohol use. Sample descriptive statistics for Positive Emotionality (M=76.9; $\mathrm{SD}=14.1$; Range $=36-$ $100)$, Negative Emotionality ( $\mathrm{M}=33.9 ; \mathrm{SD}=13.7$; Range= 13 - 93), and Constraint $(\mathrm{M}=$ 72.5; $\mathrm{SD}=12.2$; Range $=45-98)$ from the Brief Multidimensional Personality Questionnaire were comparable to published norms (Patrick, Curtin, \& Tellegen, 2002). Table 1 provides descriptive information of relevant individual difference variables separated by Beverage Group. No significant Beverage Group differences were observed for any of the alcohol use, problems and/or trait individual difference variables as expected given random assignment to Beverage Group. As expected, participants in the alcohol group tolerated significantly more shocks $(\mathrm{M}=12.7, \mathrm{SD}=5.5)$ than did participants in the placebo group $(\mathrm{M}=15.6, \mathrm{SD}=6.3)$ during the post-drinking shock tolerance assessment procedure, $\mathrm{t}(118)=2.51, \mathrm{p}=.014$. As noted earlier, shock intensity in the main experimental task was set to each participant's maximum tolerance threshold determined from this assessment to control for alcohol's analgesic effect and individual differences in shock sensitivity.

\section{Beverage Group Manipulation Checks}

For participants in the alcohol group, mean peak BAC was .081\% $(\mathrm{SD}=.014 \%$; Range $=$. $046-.115 \%)$. Their mean BAC was $.076 \%(\mathrm{SD}=.016 \%$; Range $=.039-.115 \%)$ immediately prior to the start of the main procedure and $.077 \%(\mathrm{SD}=.012 \%$; Range $=.044$ $-.105 \%)$ immediately post-procedure.

To verify the success of our placebo manipulation, we compared the alcohol and placebo groups on the three placebo manipulation check questions that were completed at the conclusion of the experiment. Participants in the alcohol group reported that their beverages contained significantly more alcohol $(\mathrm{M}=3.8$ drinks, $\mathrm{SD}=1.2$ drinks, Range $=1.5-8.0$ drinks) than placebo participants ( $\mathrm{M}=2.6$ drinks, $\mathrm{SD}=1.2$ drinks, Range $=0-7$ drinks), $\mathrm{t}(117)=5.28, \mathrm{p}<.001$. However, perceived alcohol content was significantly above 0 in both beverage groups (p's $<.001$ for one sample t-tests in each beverage group). Participants in the alcohol group reported that they were significantly more intoxicated $(\mathrm{M}=2.8, \mathrm{SD}=$ 0.7 , Range $=0.5-4.0)$, than placebo participants, $(\mathrm{M}=2.1, \mathrm{SD}=0.7$, Range $=0.0-3.0)$, $\mathrm{t}(118)=5.01, \mathrm{p}<.001$. Nonetheless, perceived level of intoxication was significantly elevated above 0 in both beverage groups ( $\mathrm{ps}<.001$ for one sample t-tests in each beverage group). Participants in the alcohol group estimated their peak BAC as significantly higher $(\mathrm{M}=.079 \%, \mathrm{SD}=.018 \%$, Range $=.04-.12 \%)$ than did placebo participants $(\mathrm{M}=.048 \%$, $\mathrm{SD}=.019 \%$, Range $=.00-.09 \%), \mathrm{t}(118)=9.21, \mathrm{p}<.001$. As with other manipulation checks, estimated BAC was significantly elevated above 0 in both beverage groups (ps < . 001 for one sample t-tests in each beverage group). Thus, an expectation of alcohol consumption and intoxication was successfully established among participants in both the alcohol and placebo groups. However, as is typical with these manipulations, we were not entirely successful in matching level of expectations regarding consumption and intoxication across the beverage groups. 


\section{Startle Potentiation during Threat Cues}

Startle potentiation during threat cues was analyzed in General Linear Models (GLM) with repeated measures on Threat Probability (100\% vs. $60 \%$ vs. $20 \%$ shock threat). Centered, orthogonal between-subject regressors for Beverage Group (Placebo vs. Alcohol), Block Order (6 orders) and Baseline Startle Response (mean-centered) and two-way interactions for all between subject regressors were included to increase power to detect Beverage Group and Threat Probability effects (Miller \& Chapman, 2001). Sex was included in preliminary models to examine potential effects of Sex on these effects. However, no significant effects of Sex were observed. Therefore, Sex was removed from the final models reported herein. Consistent with random assignment, there were no significant relationships among Beverage Group, Block Order, and Baseline Startle Response. All Beverage Group and Threat Probability effects are reported unweighted across Block Orders at mean Baseline Startle Response. Huynh-Feldt corrected p-values are reported for all multi-df effects involving Threat Probability. Raw GLM coefficients are reported to document effect sizes as appropriate.

Significant (non-zero), robust startle potentiation was observed during shock cues across threat probabilities, $\mathrm{B}=52.3 \mu \mathrm{V}, \mathrm{t}(101)=13.70, \mathrm{p}<.001$. A significant effect of Threat Probability was observed, $F(2,202)=25.61, \mathrm{p}<.001$. Startle potentiation was increased during $60 \%$ threat cues $(\mathrm{M}=60.4 \mu \mathrm{V}, \mathrm{SE}=4.2)$ and $20 \%$ threat cues $(\mathrm{M}=56.4 \mu \mathrm{V}, \mathrm{SE}=$ 4.3) relative to $100 \%$ threat cues $(\mathrm{M}=40.0 \mu \mathrm{V}, \mathrm{SE}=4.1), \mathrm{B}$ 's $=20.4 \mu \mathrm{V} \& 16.4 \mu \mathrm{V}$, t's $(101)=8.14 \& 4.92$, p's $<.001$, respectively.

The effect of Beverage Group on mean startle potentiation across threat probabilities was not significant. However, the Beverage Group $\times$ Threat Probability effect was significant, as predicted, $\mathrm{F}(2,202)=4.03, \mathrm{p}=.022$ (see Figure 2, left panel). The magnitude of the Beverage Group effect on startle potentiation increased monotonically as a function of Threat Probability (see Figure 2 right panel). The simple Beverage Group effect on startle potentiation was not significant during $100 \%$ threat cues, $\mathrm{B}=3.0 \mu \mathrm{V}, \mathrm{t}(101)=0.36, \mathrm{p}=.719$. The simple Beverage Group effect was marginal during $60 \%$ threat cues, $B=14.0 \mu \mathrm{V}$, $\mathrm{t}(101)=1.68, \mathrm{p}=.097$. The simple Beverage Group effect was significant during $20 \%$ threat cues, $\mathrm{B}=19.8 \mu \mathrm{V}, \mathrm{t}(101)=2.31, \mathrm{p}=.023$. Single degree of freedom (df) interaction contrasts confirmed that the magnitude of the Beverage Group effect was significantly greater during $60 \%$ threat cues and $20 \%$ threat cues relative to the Beverage Group effect during $100 \%$ threat cues, B's $=11.0 \mu \mathrm{V} \& 16.9 \mu \mathrm{V}, \mathrm{t}$ 's $(101)=2.20 \& 2.54, \mathrm{ps}=.030 \&<.013$, respectively.

\section{Startle Potentiation during ITls}

Comparable General Linear Models were fit and tested to examine Beverage Group and Threat Probability effects on startle potentiation during the ITI period between threat cues. As with Threat Cue analyses, Sex was included in preliminary analytic models for the ITI period. However, no significant Sex effects were observed, and it was removed from final models.

Significant (non-zero), robust startle potentiation was observed during the ITIs across threat probabilities, $\mathrm{B}=15.7 \mu \mathrm{V}, \mathrm{t}(101)=7.59, \mathrm{p}<.001$. A significant effect of Threat Probability was observed, $\mathrm{F}(2,202)=12.66, \mathrm{p}<.001$. Startle potentiation was increased during ITIs in $60 \%$ threat $(\mathrm{M}=22.8 \mu \mathrm{V}, \mathrm{SE}=2.9)$ and $20 \%$ threat $(\mathrm{M}=16.1 \mu \mathrm{V}, \mathrm{SE}=2.5)$ relative to ITIs in $100 \%$ threat $(\mathrm{M}=8.5 \mu \mathrm{V}, \mathrm{SE}=2.5)$, B's $=14.3 \mu \mathrm{V} \& 7.7 \mu \mathrm{V}, \mathrm{t}$ 's $(101)=5.03 \& 2.64$, p's $\leq .001 \& .010$, respectively (see Figure 3 , left and right panels).

In contrast to Threat Cue analyses, a significant overall effect of Beverage Group on mean startle potentiation across threat probabilities was observed during the ITIs, $B=13.4 \mu \mathrm{V}$, 
$t(101)=3.24, p=.002$. Furthermore, the Beverage Group $\times$ Threat Probability effect was not significant, $\mathrm{F}(2,202)=1.61, \mathrm{p}=.202$, suggesting comparable magnitude Beverage Group effects across all three threat probabilities. Consistent with this, the simple Beverage Group effects were significant or marginal for all three threat probabilities, $B=12.3 \mu \mathrm{V}, \mathrm{t}(101)=$ $2.48, \mathrm{p}=.015$ for ITI during $100 \%$ threat, $\mathrm{B}=19.0 \mu \mathrm{V}, \mathrm{t}(101)=3.27, \mathrm{p}=.001$ for ITI during $60 \%$ threat, $\mathrm{B}=9.0 \mu \mathrm{V}, \mathrm{t}(101)=1.78, \mathrm{p}=.078$ for ITI during $20 \%$ threat. Single $\mathrm{df}$ interaction contrasts confirmed that the magnitude of the Beverage Group effect was not significantly different during ITI in $60 \%$ threat and $20 \%$ threat relative to the Beverage Group effect during ITI in $100 \%$ threat, B's $=-6.7 \mu \mathrm{V} \& 3.3 \mu \mathrm{V}$, t's $(101)=1.18 \& 0.57$, p's $=.239 \& .570$, respectively.

\section{Individual Differences Moderators}

Exploratory analyses examined potential moderating effects of individual differences in alcohol use (Drinks/Week), alcohol problems, and personality. Separate analyses were conducted to examine the moderating effect of each individual difference measure on the significant Beverage Group effects reported earlier from the cue and ITI periods (i.e., startle potentiation during $20 \%$ threat for cue period; overall mean startle potentiation for ITI period). Each GLM included regressors for Beverage Group, the individual difference measure (mean-centered) and their interaction. As in earlier GLMs, Baseline Startle Response, Block order and their two-way interactions with other regressors in the model were included as control variables to increase power. The critical test for each model was the Beverage Group $\times$ Individual difference moderator effect.

No significant Beverage Group $\times$ Individual difference moderating effects were observed in the cue period for any of the individual difference measures. However, two significant moderators of the Beverage Group effect on startle potentiation during the ITI period were observed. Drinks/Week significantly moderated the Beverage Group effect, $B=-1.6 \mu \mathrm{V}$, $t(93)=2.39, p=.019$, indicating that the Beverage Group effect on startle potentiation in the ITI period decreased as participants reported consuming increasing number of drinks per week (see Figure 4, left panel). Negative Emotionality also significantly moderated the Beverage Group effect, $\mathrm{B}=0.7 \mu \mathrm{V}, \mathrm{t}(93)=2.11, \mathrm{p}=.037$. This indicates that the Beverage Group effect on startle potentiation in the ITI period increased as participants reported increasing Negative Emotionality (see Figure 4, right panel).

\section{Discussion}

In this report, we described results from a novel task that manipulated shock probability parametrically during brief visual cues. Threat imminence was held constant by administering all shocks at cue offset. This provided an opportunity for careful assessment of how threat probability moderated alcohol's SRD effect on startle potentiation during threat of electric shock. As predicted given its putative role in anxiety, threat probability proved to be a strong moderator on the effects of alcohol. The variable duration shock-free intervals between cues provided an opportunity to detect an alcohol SRD effect on startle potentiation in an anxious context characterized by temporally distal (non-imminent) threat. Alcohol robustly reduced startle potentiation in these intervals between cues, as predicted. Finally, the magnitude of alcohol SRD during distal/uncertain threat varied meaningfully by individual differences in negative affectivity and typical weekly alcohol consumption. In the following sections, we unpack these central results, connect the results to other relevant experiments in humans and animal models, and identify clinical implications, important limitations and, near-term future directions. 


\section{Alcohol SRD and Threat Probability during Cues}

As reviewed earlier, a growing body of evidence has suggested that fear and anxiety are distinct, dissociable processes both phenomenologically and neurobiologically (Davis et al., 2010). In particular, threat uncertainty (vs. certainty) appears to be intimately related to the elicitation of anxiety (vs. fear) (Davis et al., 2010; Grillon, 2008). In this experiment, we manipulated threat uncertainty by parametrically varying the probability of shock administration $(100 \%, 60 \%$, and 20\%), and examined alcohol SRD at these three probabilities. The magnitude of alcohol SRD, measured by startle potentiation during threat cues, varied significantly based on shock probability (Figure 2, left panel). As predicted, alcohol did not reduce startle potentiation during certain (100\%) shock cues. However, the magnitude of alcohol SRD increased monotonically as threat uncertainty increased (i.e., shock probability decreased). Alcohol produced a marginal 14 microvolt reduction in startle potentiation during $60 \%$ shock threat and a robust, significant 20 microvolt reduction in startle potentiation during $20 \%$ shock threat. Formal statistical contrasts confirmed that alcohol SRD was greater during $20 \%$ and $60 \%$ shock threat than during $100 \%$ shock threat (Figure 2, right panel).

These results provide clear evidence that the magnitude of alcohol SRD appears tightly coupled with shock probability/threat uncertainty during the cues. Such results corroborate our earlier report that alcohol SRD was observed during unpredictable but not predictable shock administration (Moberg \& Curtin, 2009). Of note, the predictable shock condition in that experiment was comparable to the $100 \%$ shock threat probability condition in the current report; however, the unpredictable shock condition used in our earlier work involved administration of shock at any point during those blocks (i.e., during cues or intervals between cues). In addition, temporal uncertainty regarding shock administration also varied between predictable blocks (no temporal uncertainty) and unpredictable blocks (high temporal uncertainty). The current report more precisely identifies shock probability as sufficient to explain the variation in the magnitude of alcohol SRD.

\section{Alcohol SRD during Distal Threat}

The shock-free intervals between cues afforded us a second opportunity to examine alcohol SRD in an anxiety-relevant context. These intervals are characterized by the anticipation of distal threat; they are of variable duration $(15-20 \mathrm{~s})$, and participants know that no shock can be administered during this time. As such, these intervals provide respite from shock threat, though anticipation of the next threat cue looms in the distance. The observed significant alcohol SRD during these intervals provides further support that alcohol reduces anxiety.

Threat imminence has been identified as an important moderator of anxiety vs. fear during defensive reactions to threat (Rau \& Fanselow, 2007). Human neuroimaging methods have detected distinct patterns of neural processing when threats are distal vs. imminent (Mobbs et al., 2007; 2009). Walker and Davis (2008) confirm selective involvement of the lateral division of the BNST during temporally uncertain, distal shock threat. Although threat imminence was not formally manipulated in our report, the consistent suppression of startle potentiation in the ITI period of all threat probability blocks by alcohol provides preliminary evidence that this period of distal threat is sensitive to alcohol's anxiolytic properties.

Across block types, the ITI represents a time when threats are on the horizon but distal, and therefore, uncertain. Increased confidence in this interpretation awaits further research that explicitly manipulates threat imminence. 


\section{SRD models and mechanisms}

The selective anxiolytic effect of alcohol observed in this and other recent experiments (Moberg \& Curtin, 2009; Hachiya et al., 2010) may provide an explanation for the inconsistency of alcohol SRD effects observed in earlier research (for reviews, see Curtin \& Lang, 2007; Greeley \& Oei, 1999). To the degree that fear and anxiety involve distinct neurobiological mechanisms, it should not be too surprising that alcohol has different effects on fear vs. anxiety. Unfortunately, researchers have often aggregated alcohol SRD results across experiments with varied procedures in attempt to reach broad conclusions about stress response dampening effects.

Consideration of this distinction between fear vs. anxiety may also clarify the mechanism proposed by influential cognitive models of the alcohol-emotion nexus (Steele \& Josephs, 1990; Sayette, 1993). Some theorists have proposed that alcohol's effect on emotional response is mediated via impairment in attention when intoxicated, such that intoxicated individuals display reduced response to threats that are presented in the periphery of salient distracters (Steele \& Josephs, 1990; see Curtin et al., 1998, 2001 for empirical support using startle potentiation). Similarly, Sayette (1993) suggested that alcohol reduces negative emotional response in contexts where threats would not be adequately appraised due to the nature and timing of these threats. It may be that salient distracters and other manipulations that degrade threat cue appraisal generally increase uncertainty regarding the nature of the threat. These threats should recruit the neural circuits involved in anxiety, which appear to be much more sensitive to alcohol. In contrast, when explicit threats are presented in the focus of attention, the onset and nature of the threat may be substantially more certain, with phasic fear response more tightly coupled to threat onset. Our research suggests that moderate doses of alcohol may selectively impact anxiety and related neural substrates, although we cannot draw firm conclusions about neurocircuitry of fear vs. anxiety based on these data alone.

\section{SRD-Relevant Individual Different Moderators}

Two significant individual difference moderators of the alcohol SRD effect during the intervals between threat cues were observed: weekly alcohol consumption and trait negative emotionality (NEM) (see Figure 4). Given the large range of typical weekly alcohol consumption reported by our sample, we were able to investigate this individual difference as a potential moderator of our primary findings on startle potentiation. In fact, weekly alcohol consumption significantly moderated the magnitude of the alcohol SRD effect during the intervals between threat cues. Reduced alcohol SRD was observed among individuals who displayed higher levels of weekly use, and we have recently observed similar moderation of the alcohol SRD effect by typical weekly alcohol use in another experiment in our laboratory (Moberg, Weber \& Curtin, 2011). This diminished SRD effect among heavy users could be interpreted as a risk factor for alcoholism within Schuckit's Low Response (LR) to Alcohol model (Schuckit et al. 2009; Schuckit \& Smith 2006), which posits that drinkers who experience reduced alcohol SRD may consume more alcohol to obtain the desired SRD effects, resulting in increasing alcohol use and concomitant problems associated with resultant heavy, hazardous drinking.

Trait negative emotionality (NEM) as assessed by the Multidimensional Personality Questionnaire also significantly moderated the magnitude of the alcohol SRD effect. Those reporting higher levels of NEM displayed the greatest reduction in startle potentiation during distal threat when intoxicated. Higher scores on NEM mark the disposition to experience negative emotions and are linked conceptually to the brain motivation system underlying defensive-withdrawal behaviors (Lang, 1995; Sutton \& Davidson, 1997; Tellegen, 1985; Watson et al., 1999). Individual differences in NEM are correlated with negative affective 
response and physiological reactions to motivationally relevant threat stimuli (Cacioppo \& Berntson, 1994; Lang, 1995; Witvliet \& Vrana, 1995). The observed moderation of alcohol SRD by NEM in this experiment suggests that individuals characterized by high trait negative emotionality may receive increased negative reinforcement from their alcohol use. This association between individual difference in NEM and alcohol SRD could contribute to the higher rates of alcohol use among individual who drink to cope with stress and their concomitant increased risk for alcohol use disorders (Cooper et al. 1995; Schroder \& Perrine 2007), and may also contribute to the increased co-morbidity between alcohol use disorders and anxiety disorders (Grant et al., 2004; Kessler et al. 1995).

Of course, speculation about causal connections among non-manipulated variables (i.e., trait negative emotionality, alcohol use, and individual differences in the alcohol SRD effect) must be advanced very cautiously until replicated in designs that can rule out alternative explanations. For example, the reduced alcohol SRD among heavy drinkers may simply reflect acquired tolerance associated with increased frequency and quantity of alcohol use. Furthermore, it must be highlighted that these individual difference moderators were observed only during distal threat associated with the intervals between cues. Similar moderation was not observed during the low probability threat cues. Explication of these nuanced differences awaits repeated testing with varied manipulations of threat uncertainty. However further investigation is warranted; initial alcohol SRD effects prior to substantial alcohol use (and the development of tolerance) should be examined as a correlate of negative emotionality and a potential prospective marker of risk for subsequent heavy alcohol use and alcohol problems.

Important questions remain regarding the relationships between startle potentiation and the neuroendocrine stress response, the effect of threat uncertainty on neuroendocrine stress response, and stress neuroendocrine response mediates the effect of alcohol on startle potentiation. In other research with both animals and humans, alcohol administration results in release of stress horomones such as adrenocorticotropic hormone (ACTH) and glucocorticoids. However, chronic heavy alcohol use also appears to suppress hypothalamicpituitary-adrenal (HPA) axis response to stressors (e.g., Adinoff et al., 2005; Richardson et al., 2008). We did not measure neuroendocrine stress response in the current study. However, other research from our laboratory has observed consistent increase across both startle potentiation and salivary cortisol measures among nicotine deprived smokers (Hogle $\&$ Curtin, 2006). Future research should examine acute alcohol administration's simultaneous effect on startle potentiation and relevant stress hormones during uncertain threat to future clarify the neurobiological mechanism of these effects.

\section{Implications for Psychiatric Disorder Etiology and Comorbidity}

The results from this experiment fit within a program of research to identify etiologic processes in addiction. Contemporary neuroscience theories and empirical evidence implicate neuroadaptation in the stress response as a critical mechanism in addiction etiology across addictive drugs including alcohol, benzodiazepines, opiates, cocaine, nicotine, and marijuana (Breese et al. 2010; Koob \& LeMoal, 2008; Shaham \& Hope, 2005; Sinha, 2008; Weiss et al., 2001). Repeated homeostatic adjustments in the brain's stress systems during periods of drug use eventually lead to chronic compensatory adaptations in the structures involved in emotional response and its regulation. These adaptations persist beyond periods of acute use and result in dysregulated negative affect (e.g., increased anxiety) and strong craving on cessation of use (Koob \& LeMoal, 2001; 2008).

Programmatic laboratory drug administration and drug deprivation studies with varied drugs in humans and animal models have begun to explicate and test for these stress neuroadaptation mechanisms. 
Results from this report corroborate other recent research to suggest that alcohol administration selectively reduces startle potentiation during unpredictable, low probability, distal, or otherwise uncertain threats in humans (Moberg \& Curtin, 2009; Hachiya et al., 2010). Similarly, others have demonstrated that benzodiazepine administration (diazepam, alprazolam) selectively reduces startle potentiation during uncertain threat (e.g., unpredictable shock, darkness), but not during cues that predict imminent, high probable shock (Baas et al., 2002; Grillon et al., 2006). These acute SRD effects of alcohol and other anxiolytic drugs may engender the homeostatic, compensatory stress neuroadaptations that result in exaggerated stress response following chronic drug use. In fact, we have recently confirmed increased startle potentiation selectively during unpredictable but not predictable shock administration among 24 hour nicotine deprived smokers (Hogle, Kaye \& Curtin, 2010), and have observed selective increases in startle potentiation during cues that predict low probable (20\%) but not high probable (100\%) shock after three days of marijuana deprivation among heavy daily marijuana users (Gloria et al., 2009).

Animal models have implicated uncertain threat and more precisely identified CRF and NE pathways in the BNST in drug administration, withdrawal, and reinstatement. NE and CRF pathways in the BNST are critically involved in stress induced reinstatement to cocaine and heroin use in rats (for review, see Shaham, Erb \& Stewart, 2000); the injection of a CRF antagonist (D-PheCRF $12-41$ ) into the BNST prevents stress-induced reinstatement for cocaine (Erb \& Stewart, 1999). In addition, neurochemical lesions of the BNST-projecting ventral noradrenergic bundle block stress-induced reinstatement for heroin (Shaham et al., 2000). Unpredictable footshock reinstates nicotine seeking behavior in nicotine-dependent mice (Plaza-Zabala et al., 2010). Nicotine deprivation selectively increases light-enhanced startle in nicotine dependent rats (Jonkman et al., 2008).

As evidenced above, this growing body of evidence specifically implicates the BNST (and more generally, NE and CRF pathways in the extended amygdala) in anxiety.

Neuroadaptations in this system are increasingly highlighted in addiction etiology. Startle potentiation during uncertain threat may thus be a valuable cross-species biomarker of the neuroadaptive changes in anxiety that result from chronic drug administration and increase risk for relapse.

As aforementioned, the observed SRD effect of alcohol in conditions selectively characterized by anxiety during uncertain threat in this experiment and the moderating role of trait negative emotionality on this selective alcohol SRD effect may partially explain the observed pattern of psychiatric comorbidity between alcohol use disorders and various anxiety disorders. Both generalized anxiety disorder (GAD) and post-traumatic stress disorder (PTSD) are highly comorbid with alcohol use disorders (Grant et al., 2005; Kessler et al., 1995). In contrast, the prevalence of alcohol use disorders is not elevated among individuals with simple phobias (Kushner et al., 1990). Unlike simple phobias, both GAD and PTSD appear to involve sustained negative affective response in complex multimodal contexts without simple, distinct cues to identify the explicit nature and timing of the potential threat. In fact, manipulations involving unpredictable threat have been used as laboratory analogs of these disorders (Grillon, 2002). Our results suggest that alcohol may be particularly effective at reducing the intensity of negative affective response for patients with these disorders, providing a strong motive for frequent and/or heavy use in order to "self-medicate." In addition, the stress neuroadaptation hypothesis described above suggests that chronic alcohol (or other drug use) may ultimately exacerbate anxious symptoms in PTSD and GAD patients during periods of deprivation, which could provide strong motivation for alcohol and/or drug use among these patients. In contrast, patients will simple phobias may be less susceptible to drinking to obtain reinforcing SRD effects of alcohol if alcohol does not affect fear response to distinct cues that predict imminent threat. 


\section{Limitations and Future Directions}

The experiment described in this report focused on a manipulation of shock probability to induce threat uncertainty and associated anxiety. Unambiguous interpretation of the role of 'threat uncertainty' as a moderator of alcohol SRD awaits considerable conceptual replication. To date, we have published one other report demonstrating alcohol SRD during uncertain threat (Moberg \& Curtin, 2009), using a previously validate paradigm involving unpredictable shock administration (Grillon et al., 2004). We have also recently observed selective alcohol SRD during temporally uncertain threat (Hachiya et al., 2010), and are currently examining alcohol SRD during threat uncertainty involving manipulations of uncertain intensity threat and uncertain spatial threat. In addition, other researchers examining basic anxiety processes in humans have developed threat uncertainty paradigms involving darkness (Grillon et al., 2007a) and CO2 challenge (Zvolensky et al., 1999). Alcohol SRD effects in these paradigms should be explored as well. The use of varied manipulations of threat uncertainty will allow better precision in our understanding of these effects and clear demarcation of their boundary conditions.

The effects of alcohol dose during threat uncertainty remain to be investigated. Both our previous work (Mober \& Curtin, 2009) and the current experiment examined only one moderate dose of alcohol (target blood alcohol concentration of .08\%). Dose has been identified as a potentially important moderator of alcohol SRD generally (Sher, 1987). It will clearly be important to explicitly examine alcohol dose response on SRD during threat uncertainty to explicate its pharmacokinetics. In other research, we have demonstrated alcohol SRD effects during well-defined, unambiguously threatening stimuli at higher BACs (Donohue et al., 2006; Moberg, Weber, \& Curtin, in press). Empirical confirmation of dose response effects on alcohol SRD have been demonstrated by others well (Sher et al. 1986; Stewart et al. 1992). However, dose response alcohol SRD during uncertain threat has not been examined and remains as an important future direction.

It is now possible to assess alcohol and other drug use in response to real world stressors in participants' day-to-day lives using ecological momentary assessment methods (Bopp et al. 2010; McCarthy et al. 2006; Piper et al. 2008). Stressor-drinking covariation is greater among individuals who develop alcohol problems (Schroder \& Perrine, 2007). Future work investigating whether individual differences in alcohol SRD effects measured in the laboratory predict real world drinking, and SRD-motivated drinking in particular, would increase the clinical relevance of these laboratory-based approaches.

\section{Summary}

In this report, we reviewed recent evidence that fear and anxiety can be dissociated, both phenomenologically and neurobiologically. We manipulated threat uncertainty via shock threat probability and examined alcohol SRD effects across this shock threat probability continuum. We demonstrated selective alcohol SRD during low probability, uncertain threat, and provided preliminary evidence of alcohol SRD during distal threat. Both trait negative emotionality and typical weekly alcohol consumption moderated this latter effect. These selective effects may explain previous inconsistency in the literature on alcohol SRD. Moreover, these results provide clear direction for future research on the cognitive and neural mechanisms of alcohol's actions in humans. Clinically, these results provide insight into patterns of alcohol use disorder comorbidity with anxiety disorders. More broadly, this program of research incrementally advances our understanding of the motivation to use alcohol and the contribution of stress neuroadaptations to the etiology of human addiction. 


\section{Acknowledgments}

Funding was provided by a grant to J. Curtin from NIAAA (R01 AA15384). Allison Grant and Jason Jaber provided substantial assistance with data collection.

\section{References}

Adinoff B, Junghanns K, Kiefer F, Krishnan-Sarin S. Supression of HPA Axis Stress Response: Implications for Relapse. Alcoholism, Clinical, and Experimental Research. 2005; 24(12):18361849.

Baker TB, Piper ME, McCarthy DE, Majeskie MR, Fiore MC. Addiction motivation reformulated: An affective processing model of negative reinforcement. Psychology Review. 2004; 111:33-51.

Baas JM, Grillon C, Böcker KB, Brack AA, Morgan CA 3rd, Kenemans JL, Verbaten MN. Benzodiazepines have no effect on fear-potentiated startle in humans. Psychopharmacology (Berlin). 2002; 161(3):233-247. [PubMed: 12021826]

Blumenthal TD, Cuthbert BN, Filion DL, Hackley S, Lipp OV, van Boxtel A. Committee report: Guidelines for human startle eyeblink electromyographic studies. Psychophysiology. 2005; 42(1):115. [PubMed: 15720576]

Bopp JM, Miklowitz DJ, Goodwin GM, Stevens W, Rendell JM, Geddes JR. The longitudinal course of of bipolar disorder as revealed through weekly text messaging: a feasibility study. Bipolar Disorders. 2010; 12:327-334. [PubMed: 20565440]

Breese GR, Singha R, Heilig M. Chronic alcohol neuroadaptation and stress contribute to susceptibility to alcohol craving and relapse. Pharmacology and Therapeutics. 2010 Epub ahead of print.

Brown SA, Vik PW, McQuaid JR, Patterson TL, Irwin MR, Grant I. Severity of psychosocial stress and outcome of alcoholism treatment. Journal of Abnormal Psychology. 1990; 99(4):344-348. [PubMed: 2266207]

Brown SA, Vik PW, Patterson TL, Grant I, Schuckit MA. Stress, vulnerability, and adult alcohol relapse. Journal of Studies on Alcohol. 1995; 56:538-545. [PubMed: 7475034]

Cacioppo JT, Berntson GG. Relationships between attitudes and evaluative space: A critical review with emphasis on the separability of positive and negative substrates. Psychological Bulletin. 1994; 115:401-423.

Cooper ML, Frone MR, Russell M, Mudar P. Drinking to regulate positive and negative emotions: a motivational model of alcohol use. Journal of Personality and Social Psychology. 1995; 69(5): 990-1005. [PubMed: 7473043]

Cornwell BR, Echiverri AM, Covington MF, Grillon C. Modality-specific attention under imminent but not remote threat of shock. Psychological Science. 2008; 19(6):615-622. [PubMed: 18578853]

Curtin JJ, Lang AR, Patrick CJ, Stritzke WGK. Alcohol and fear-potentiated startle: The role of competing cognitive demands in the stress-reducing effects of intoxication. Journal of Abnormal Psychology. 1998; 107(4):547-565. [PubMed: 9830242]

Curtin JJ, Lang AR, Patrick CJ, Cacioppo JT, Birbaumer N. Alcohol affects emotion through cognition. Psychological Science. 2001; 12(6):527-531. [PubMed: 11760143]

Curtin JJ, Fairchild BA. Alcohol and cognitive control: Implications for regulation of behavior during response conflict. Journal of Abnormal Psychology. 2003; 112(3):424-436. [PubMed: 12943021]

Curtin JJ, Lang AR. Alcohol and emotion: Insights and directives from affective science. Emotion and Psychopathology: Bridging Affective and Clinical Science. 2007; 8:191-213.

Davis M. Neural systems involved in fear and anxiety measured with fear-potentiated startle. American Psychologist. 2006; 61(8):741-756. [PubMed: 17115806]

Davis M, Antoniadis EA, Amaral DG, Winslow JT. Acoustic startle reflex in rhesus monkeys: A review. Reviews in the Neurosciences. 2008; 19:171-185. [PubMed: 18751523]

Davis M, Walker DL, Miles L, Grillon C. Phasic vs sustained fear in rats and humans: The role of the extended amygdala in fear vs anxiety. Neuropsychopharmacology. 2010; 35(1):105-135. [PubMed: 19693004] 
Delgado MR, Olsson A, Phelps EA. Extending animal models of fear conditioning to humans. Biological Psychology. 2006; 73:39-48. [PubMed: 16472906]

Donohue KF, Curtin JJ, Patrick CJ, Lang AR. Intoxication Level and Emotional Response. Emotion. 2007; 7:103-112. [PubMed: 17352567]

Erb S, Stewart J. A role for the bed nucleus of the stria terminalis, but not the amygdala, in the effects of corticotropin-releasing factor on stress-induced reinstatement of cocaine seeking. Journal of Neuroscience. 1999; 19(RC35):1-6. [PubMed: 9870932]

Gloria R, Jaber JN, Baker TB, Curtin JJ. The effect of temporal precision and probability on the response to threat of shock: a fear-potentiated startle study. Psychophysiology. 2009; 46(s1):s80.

Goldman, MS.; Brown, SA.; Christiansen, BA. Expectancy theory: Thinking about drinking. In: Blane, HT.; Leonard, KE., editors. Psychological theories of drinking and alcoholism. Guilford Press; New York: 1987. p. 181-226.

Grant BF, Stintson FS, Dawson DA, Chou P, Dufour MC, Compton W, Pickering RP, Kaplan K. Prevalence and co-occurrence of substance use disorders and independent mood and anxiety disorders. Archives of General Psychiatry. 2004; 61:807-816. [PubMed: 15289279]

Grillon C, Sinha R, O'Malley SS. Effects of ethanol on the acoustic startle reflex in humans. Psychopharmacology (Berlin). 1994; 114(1):167-71. [PubMed: 7846199]

Grillon C, Pellowski M, Merikangas KR, Davis M. Darkness facilitates the acoustic startle reflex in humans. Biological Psychiatry. 1997; 42:453-460. [PubMed: 9285081]

Grillon C, Sinha R, Ameli R, O'Malley SS. Effects of alcohol on baseline startle and prepulse inhibition in young men at risk for alcoholism and/or anxiety disorders. Journal of Studies on Alcohol. 2000; 61(1):46-54. [PubMed: 10627096]

Grillon C. Startle reactivity and anxiety disorders: Aversive conditioning, context, and neurobiology. Biological Psychiatry. 2002; 52(10):958-975. [PubMed: 12437937]

Grillon C, Baas JP, Lissek S, Smith K, Milstein J. Anxious responses to predictable and unpredictable aversive events. Behavioral Neuroscience. 2004; 118:916-924. [PubMed: 15506874]

Grillon C, Baas JM, Cornwell B, Johnson L. Context conditioning and behavioral avoidance in a virtual reality environment: effect of predictability. Biological Psychiatry. 2006a; 60(7):752-759. [PubMed: 16950216]

Grillon C, Baas JM, Pine DS, Lissek S, Lawley M, Ellis V, Levine J. The benzodiazepine alprazolam dissociates contextual fear from cued fear in humans as assessed by fear-potentiated startle. Biological Psychiatry. 2006b; 60(7):760-766. [PubMed: 16631127]

Grillon C, Duncko R, Covington MF, Kopperman L, Kling MA. Acute stress potentiates anxiety in humans. Biological Psychiatry. 2007a; 62:1183-1186. [PubMed: 17692829]

Grillon C, Avenevoli S, Daurignac E, Merikangas KR. Fear-potentiated startle to threat, and prepulse inhibition among young adult nonsmokers, abstinent smokers, and nonabstinent smokers. Biological Psychiatry. 2007b; 62(10):1155-1161. [PubMed: 17543892]

Grillon C. Models and mechanisms of anxiety: evidence from startle studies. Psychopharmacology. 2008; 199:421-437. [PubMed: 18058089]

Hachiya LY, Moberg CA, Curtin JJ. Alcohol effects on affective response during variable and fixed duration threat. Alcoholism: Clinical and Experimental Research. 2010; 34(s2):117A.

Hasler G, Fromm S, Alvarez RP, Luckenbaugh DA, Drevets WC, Grillon C. Cerebral blood flow in immediate and sustained anxiety. The Journal of Neuroscience. 2007; 27:6313-6319. [PubMed: 17554005]

Herry C, Back DR, Esposito F, Di Salle F, Perrig W, Scheffler K, Luthi A, Seifritz E. Processing of temporal unpredictability in human and animal amygdala. The Journal of Neuroscience. 2007; 27(22):5958-5966. [PubMed: 17537966]

Hogle JM, Kaye J, Curtin JJ. Nicotine withdrawal increases threat-induced anxiety but not fear: Neuroadaptation in human addiction. Biological Psychiatry. 2010; 68(8):719-725. [PubMed: 20673878]

Hogle JM, Curtin JJ. Sex differences in negative affective response during nicotine withdrawal. Psychophysiology. 2006; 43:344-356. [PubMed: 16916430]

Hsu M, Bhatt M, Adolphs R, Tranel D, Camerer CF. Neural systems responding to degrees of uncertainty in human decision-making. Science. 2005; 310:1680-1683. [PubMed: 16339445] 
Huettel SA, Stowe CJ, Gordon EM, Warner BT, Platt ML. Neural signatures of economic preferences for risk and ambiguity. Neuron. 2006; 49:765-775. [PubMed: 16504951]

Hurlbut SC, Sher KJ. Assessing alcohol problems in college students. Journal of American College Health. 1992; 41(2):49-58. [PubMed: 1460173]

Jonkman S, Risbrough VB, Geyer MA, Markou A. Spontaneous nicotine withdrawal potentiates the effects of stress in rats. Neuropsychopharmacology. 2008; 33:2131-2138. [PubMed: 18033237]

Kessler RC, Sonnega A, Bromet E, Hughes M, Nelson CB. Posttraumatic stress disorder in the National Comorbidity Survey. Archives of General Psychiatry. 1995; 52:1048-1060. [PubMed: 7492257]

Lang PJ. The emotion probe: Studies of motivation and attention. American Psychologist. 1995; 50:372-385. [PubMed: 7762889]

Koob GF, LeMoal M. Drug addiction, dysregulation of reward, and allostasis. Neuropsychopharmacology. 2001; 24(2):97-129. [PubMed: 11120394]

Koob GF, Le Moal M. Addiction and the brain antireward system. Annual Reviews of Psychology. 2008; 59:29-53.

Lê AD, Quan B, Juzytch W, Fletcher PJ, Joharchi N, Shaham Y. Reinstatement of alcohol-seeking by priming injections of alcohol and exposure to stress in rats. Psychopharmacology. 1998; 135:169174. [PubMed: 9497022]

LeDoux J. The neural circuits underlying anxiety and fear. Fear and the brain: Where have we been, and where are we going? Biological Psychiatry. 1998; 44:1229-1238. [PubMed: 9861466]

Liang KC, Melia KR, Miserendino MJ, Falls WA, Campeau S, Davis M. Corticotropin-releasing factor: Long-lasting facilitation of the acoustic startle reflex. The Journal of Neuroscience. 1992; 12:2303-2312. [PubMed: 1351540]

McCarthy DE, Piasecki TM, Fiore MC, Baker TB. Life before and after quitting smoking: An electronic diary study. Journal of Abnormal Psychology. 2006; 115:454-66. [PubMed: 16866586]

Miller GA, Chapman JP. Misunderstanding analysis of covariance. Journal of Abnormal Psychology. 2001; 110(1):40-48. [PubMed: 11261398]

Moberg CA, Curtin JJ. Alcohol selectively reduces anxiety but not fear: startle response during unpredictable versus predictable threat. Journal of Abnormal Psychology. 2009; 118(2):335-347. [PubMed: 19413408]

Moberg CA, Weber S, Curtin JJ. Alcohol dose effects on stress response to cued threat vary by threat intensity. Psychopharmacology. 2011

Mol N, Baas JMP, Grillon C, van Ooijen L, Kenemans JL. Startle potentiation in rapidly alternating conditions of high and low predictability of threat. Biological Psychiatry. 2007; 76:43-51.

Overstreet DH, Knapp DJ, Breese GR. Drug challenges reveal differences in mediation of stress facilitation of voluntary alcohol drinking and withdrawal-induced anxiety in alcohol-preferring $\mathrm{P}$ rats. Alcoholism: Clinical and Experimental Research. 2007; 31(9):1473-1481.

Patrick CJ, Curtin JJ, Tellegen A. Development and validation of a brief form of the Multidimensional Personality Questionnaire. Psychological Assessment. 2002; 14(2):150-163. [PubMed: 12056077]

Phelps EA. Emotion and cognition: Insights from studies of the human amygdala. Annual Reviews of Psychology. 2006; 57:27-53.

Piper ME, Federmen EB, McCarthy DE, Bolt DM, Smith SS, Fiore MC, Baker TB. Using mediational models to explore the nature of tobacco motivation and tobacco treatment effects. Journal of Abnormal Psychology. 2008; 117:94-105. [PubMed: 18266488]

Plaza-Zabala A, Martín-Garcia E, de Lecea L, Maldonado R, Berrendero F. Hypocretins regulate the anxiogenic-like effects of nicotine and induced reinstatement of nicotine-seeking behavior. The Journal of Neuroscience. 2010; 30:2300-2310. [PubMed: 20147556]

Rau, V.; Fanselow, MS. Neurobiological and neuroethological perspectives on fear and anxiety. In: Kirmayer, LJ.; Lemesom, R.; Barad, M., editors. Understanding trauma: integrating biological, clinical, and cultural perspectives. Cambridge UP; New York: 2007. p. 27-40.

R Development Core Team. R: A language and environment for statistical computing. R Foundation for Statistical Computing; Vienna, Austria: 2009. URL http://www.R-project.org 
Richardson HN, Lee SY, O’Dell LE, Koob GE, Rivier CL. Alcohol self-administration acutely stimulates the hypothalamic-pituitary-adrenal axis, but alcohol dependence leads to a dampened neuroendocrine state. European Journal of Neuroscience. 2008; 28(8):1641-1653. [PubMed: 18979677]

Sarinopoulos I, Grupe DW, Mackiewicz KL, Herrington JD, Lor M, Steege EE, Nitschke JB. Uncertainty during anticipation modulates neural responses to aversion in human insula and amygdala. Cerebral Cortex. 2010; 20(4):929-940. [PubMed: 19679543]

Sayette MA. An appraisal-disruption model of alcohol's effects on stress responses in social drinkers. Psychological Bulletin. 1993; 114:459-476. [PubMed: 8272466]

Schroder KE, Perrine MW. Covariations of emotional states and alcohol consumption: evidence from 2 years of daily data collection. Social Science \& Medicine. 2007; 65(12):2588-2602. [PubMed: 17761376]

Selzer ML, Vinokur A, van Rooijen L. A self-administered short Michigan alcoholism screening test. Journal of Studies on Alcohol. 1975; 36(1):117-126. [PubMed: 238068]

Shaham Y, Erb S, Stewart J. Stress-induced relapse to heroin and cocaine seeking in rats: a review. Brain Research Reviews. 2000; 33:13-33. [PubMed: 10967352]

Shaham Y, Highfield D, Delfs J, Leung S, Stewart J. Clonidine blocks stress-induced reinstatement of heroin seeking in rats: an effect independent of locus coeruleus noradrenergic neurons. European Journal of Neuroscience. 2000; 12:292-302. [PubMed: 10651884]

Shaham Y, Hope BT. The role of neuroadaptations in relapse to drug seeking. Nature Neuroscience. 2005; 8:1437-1439.

Sher, KJ. Stress response dampening. In: Blane, HT.; Leonard, KE., editors. Psychological theories of drinking and alcoholism. Guilford Press; New York: 1987. p. 227-271.

Sher KJ, Walitzer KS. Individual differences in the stress-response dampening effect of alcohol: A dose-response study. Journal of Abnormal Psychology. 1986; 95:159-167. [PubMed: 3711440]

Sinha R. Chronic stress, drug use, and vulnerability to addiction. Annals of the New York Academy of Science. 2008; 1141:105-130.

Solomon RL, Corbit JD. An opponent-process theory of motivation: temporal dynamics of affect. Psychological Review. 1974; 81(2):119-145. [PubMed: 4817611]

Smith RJ, Aston-Jones G. Noradrenergic transmission in the extended amygdala: role in increased drug-seeking and relapse during protracted abstinence. Brain Structure and Function. 2008; 213:43-61. [PubMed: 18651175]

Steele C, Josephs R. Alcohol myopia: Its prized and dangerous effects. American Psychologist. 1990; 45:921-933. [PubMed: 2221564]

Stewart SH, Finn PR, Pihl RO. The effects of alcohol on the cardiovascular stress response in men at high risk for alcoholism: A dose response study. Journal of Studies on Alcohol. 1992; 53:499-506. [PubMed: 1405644]

Sutton SK, Davidson RJ. Prefrontal brain asymmetry: A biological substrate of the behavioral approach and inhibition systems. Psychological Science. 1997; 8:204-210.

Swerdlow NR, Geyer MA, Vale WW, Koob GF. Corticotropin-releasing factor potentiates acoustic startle in rats: blockade by chlordiazepoxide. Psychopharmacology. 1986; 88:147-152. [PubMed: 3081925]

Tellegen, A. Structures of mood and personality and their relevance to assessing anxiety, with an emphasis on self-report. In: Tuma, AH.; Maser, JD., editors. Anxiety and the Anxiety Disorders. Erlbaum; Hillsdale, NJ: 1985. p. 681-706.

Tinn-R Development Team. Tinn-R: A editor for R language and environment statistical computing. 2004. URL http://www.sciviews.org/Tinn-R/ and http://sourceforge.net/projects/tinn-r

Upile T, Sipaul F, Jerjes W, Singh S, Nouraei SA, El Maaytah M, et al. The acute effects of alcohol on auditory thresholds. BMC Ear, Nose, and Throat Disorders. 2007; 7:4.

Volkow ND, Li TK. Drug addiction: The neurobiology of behavior gone awry. Nature Reviews Neuroscience. 2004; 5:963-970.

Walker DL, Davis M. Role of the extended amygdala in short-duration versus sustained fear: a tribute to Dr. Lennart Heimer. Brain Structure \& Function. 2008; 213:29-42. [PubMed: 18528706] 
Walker DL, Toufexis DJ, Davis M. Role of the bed nucleus of the stria terminalis versus amygdala in fear, stress, and anxiety. European Journal of Pharmacology. 2003; 463:199-216. [PubMed: 12600711]

Walker DL, Davis M. Anxiogenic effects of high illumination levels assessed with the acoustic startle response in rats. Biol Psychiatry. 1997; 42:461-471. [PubMed: 9285082]

Watson D, Wiese D, Vaidya J, Tellegen A. The two general activation systems of affect: Structural findings, evolutionary considerations, and psychobiological evidence. Journal of Personality and Social Psychology. 1999; 76:820-838.

Weiss F, Ciccocioppo R, Parsons LH, Katner S, Liu X, Zorrilla EP, et al. Compulsive drug-seeking behavior and relapse: Neuroadaptation, stress, and conditioning factors. Annals of the New York Academy of Sciences. 2001; 937:1-26. [PubMed: 11458532]

Witvliet CV, Vrana SR. Psychophysiological responses as indices of affective dimensions. Psychophysiology. 1995; 32:436-443. [PubMed: 7568637]

Zvolensky MJ, Eifert GH, Lejuez CW, McNeil DW. The effects of offset control over 20\% carbondioxide-enriched air on anxious responding. Journal of Abnormal Psychology. 1999; 108(4):624632. [PubMed: 10609427]

Zvolensky M, Lejuez C, Eifert G. Prediction and control: operational definitions for the experimental analysis of anxiety. Behaviour Research and Therapy. 2000; 38:653-663. [PubMed: 10875188] 

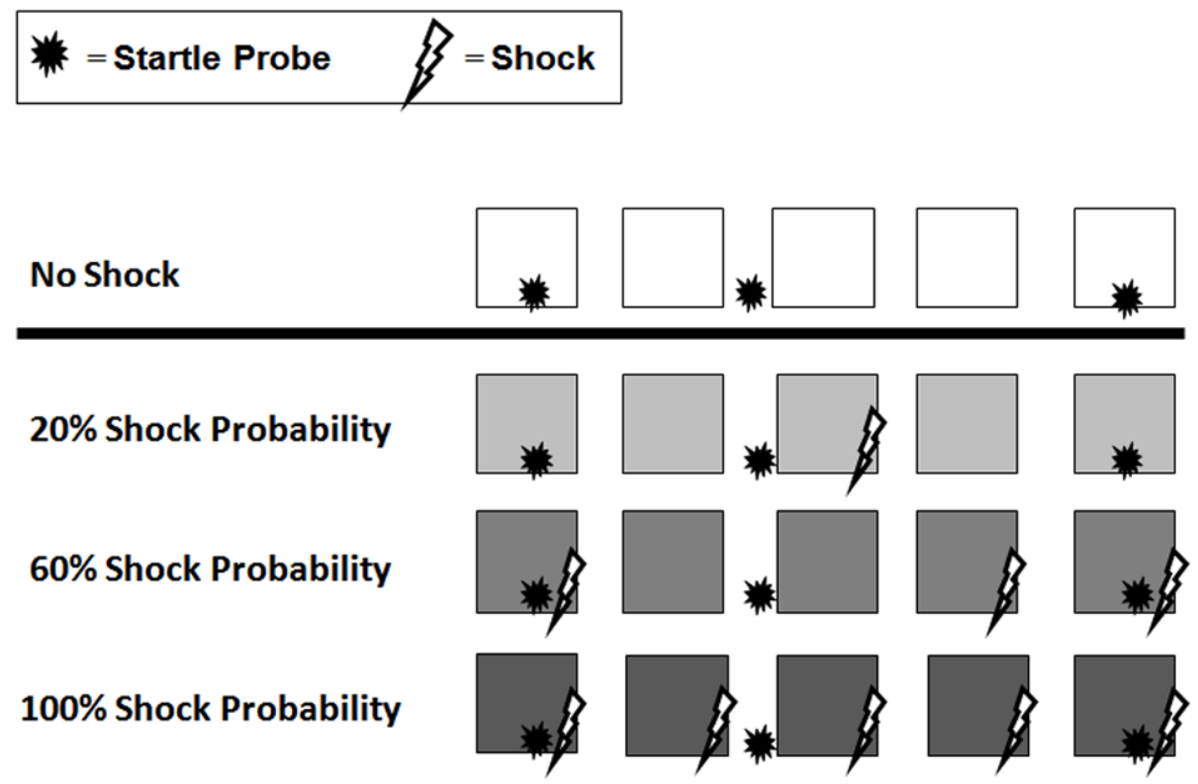

Figure 1. Task Design Schematic

The task involved presentation of blocks of colored square cues presented for $5 \mathrm{~s}$ each, separated by a variable duration inter-trial interval (ITI; range $=15-20 \mathrm{~s}$ ). Cues were blocked into three Threat Probability conditions (100\% vs. $60 \%$ vs. $20 \%)$ that indicated the probability of shock administration (at $4.5 \mathrm{~s}$ post-cue onset) during any discrete cue in that block. Blocks of no-shock cues were also presented to calculate startle potentiation associated with shock threat. Unique colors (indicated by grayscale in figure) were associated with each cue type. The startle response was elicited by white noise probes presented during cues (at $4 \mathrm{~s}$ post-cue onset) and ITI periods between cues (at 13 or $15 \mathrm{~s}$ post-cue offset). 

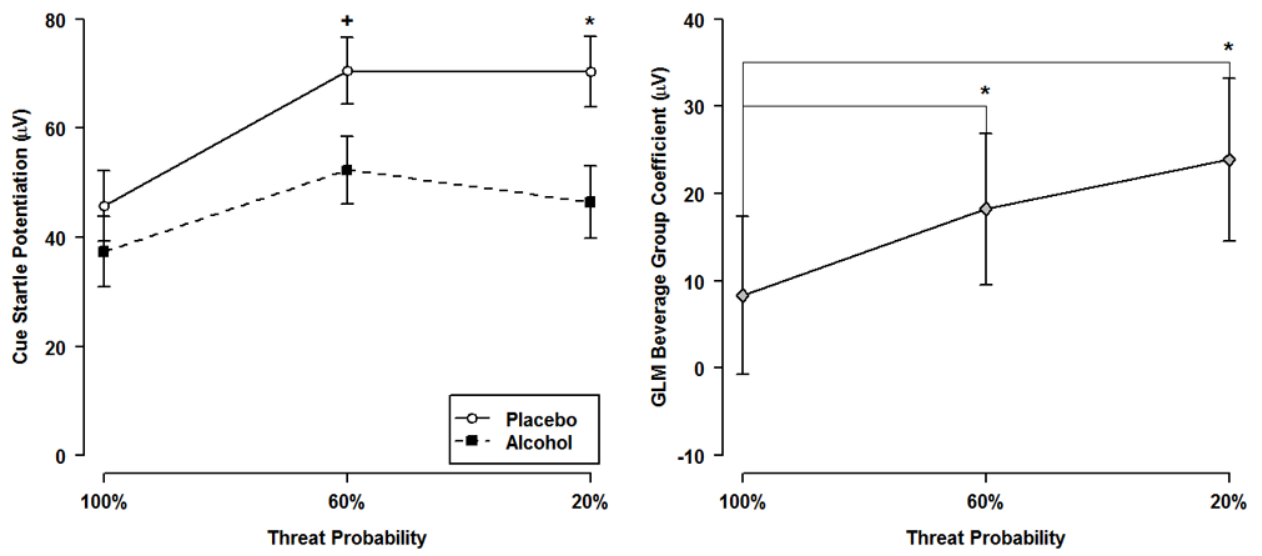

Figure 2. Beverage Group and Threat Probability Effects on Startle Potentiation during Cues Left Panel Startle potentiation scores during threat cues are displayed by Threat Probability. The Beverage Group X Threat Probability interaction was significant ( $\mathrm{p}=.022)$. Follow-up tests revealed a significant Beverage Group simple effect during 20\% threat $(\mathrm{p}=.023)$ and a marginal Beverage Group simple effect during 60\% threat $(\mathrm{p}=.097)$. The Beverage Group simple effect was not significant during $100 \%$ threat $(\mathrm{p}=.719)$. Error bars represent the standard errors for the startle potentiation point estimates from the General Linear Model. Significant and marginal simple Beverage Group effects are indicated $(+\mathrm{p} \leq .10, * \mathrm{p} \leq .05)$. Right Panel: General Linear Model (GLM) Beverage Group Coefficients are displayed by Threat Probability. The Beverage Group GLM coefficients indicate the magnitude by which startle potentiation during threat cues was reduced in the alcohol group relative to the placebo group. The magnitude of this Beverage Group effect monotonically increased with decreasing threat probability. Single degree of freedom coefficient contrasts indicated that the Beverage Group effects during $20 \%$ threat and $60 \%$ threat were both significantly greater than the Beverage group effect during $100 \%$ threat (ps $\leq .013 \& .030$, respectively). Error bars represent the standard errors for the Beverage Group coefficients. Significant and marginal Beverage Group coefficient contrasts are indicated (* $\mathrm{p} \leq .05$ ). 

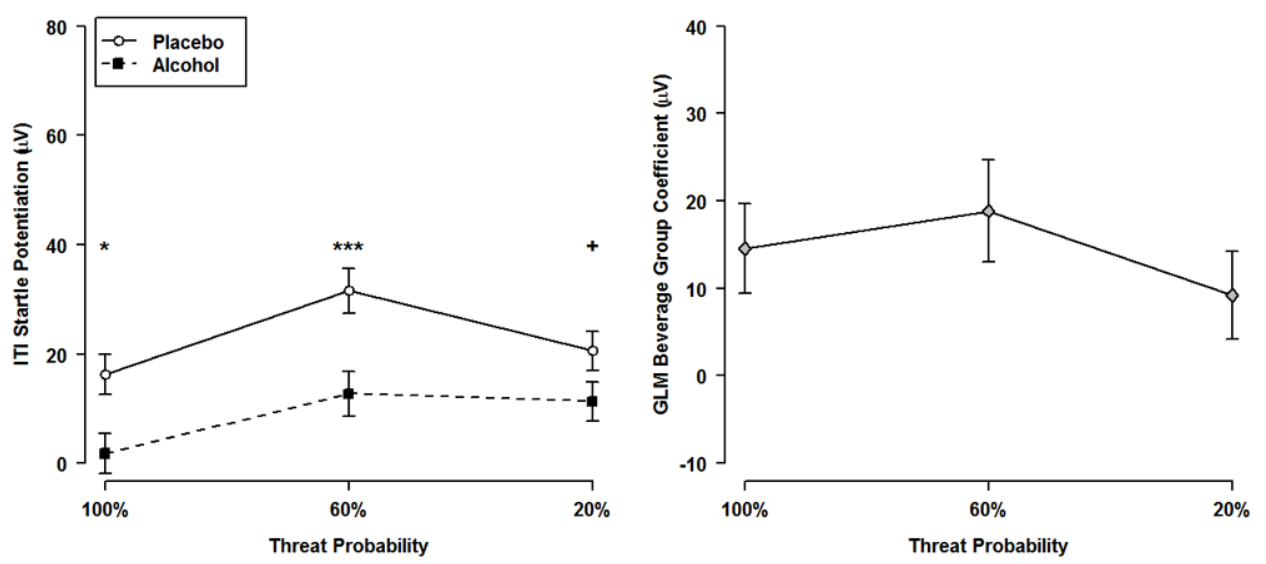

Figure 3. Beverage Group and Threat Probability Effects on Startle Potentiation during Shockfree Inter-Trial-Intervals

Left Panel: Startle potentiation scores during the inter-trial intervals (ITIs) between threat cues are displayed by Threat Probability. No shocks were administered during the ITIs. The Beverage Group effect was significant $(\mathrm{p}=.002)$ indicating that alcohol reduced startle potentiation across all threat probability blocks. In addition, significant or marginal Beverage Group simple effects were observed for all threat probability blocks (ps $=.015$, . $001, \& .078$ for $100 \%, 60 \%$ and $20 \%$ respectively). Error bars represent the standard errors for the startle potentiation point estimates from the General Linear Model. Significant and marginal simple Beverage Group effects are indicated $(+\mathrm{p} \leq .10, * \mathrm{p} \leq .05, * * * \mathrm{p} \leq .001)$. Right Panel: General Linear Model (GLM) Beverage Group Coefficients are displayed by Threat Probability. The Beverage Group GLM coefficients indicate the magnitude by which startle potentiation during the inter-trial-intervals was reduced in the alcohol group relative to the placebo group. None of the single degree of freedom coefficient contrasts across threat probabilities were significant, indicating that Beverage Group effects were comparable across threat probabilities. Error bars represent the standard errors for the Beverage Group coefficients. 

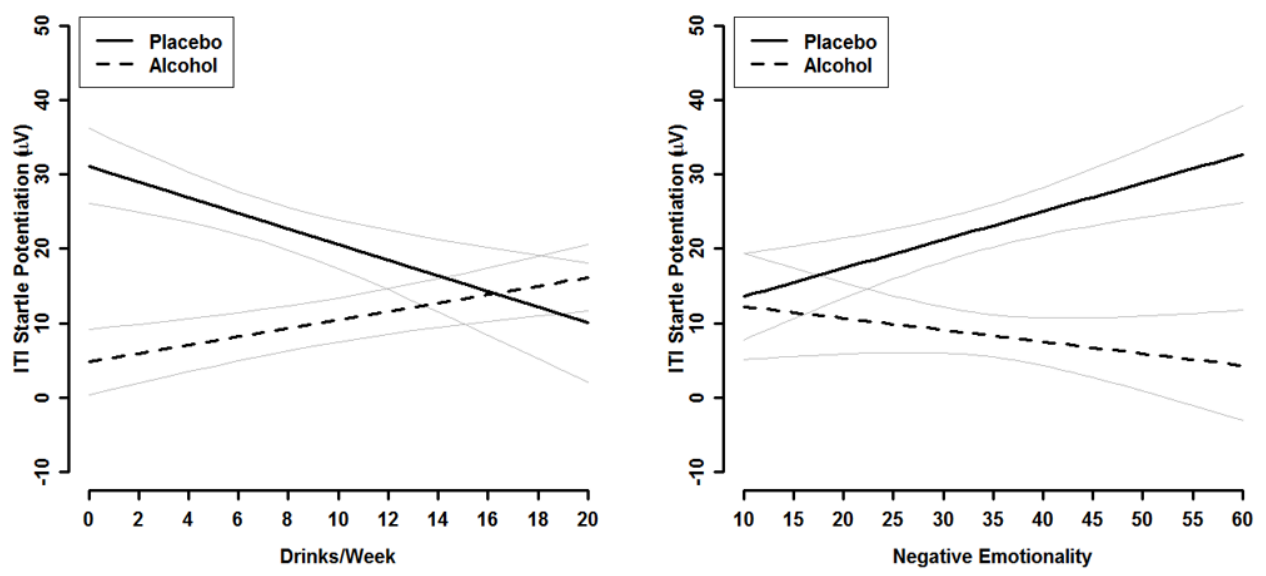

Figure 4. Individual Difference Moderators of Beverage Group Effects on Inter-Trial Interval Startle Potentiation

Left Panel: Mean ITI startle potentiation scores are displayed by Beverage Group and typical weekly alcohol consumption (drinks per week). The Beverage Group X Drinks/week interaction was significant $(\mathrm{p}=.019)$, with Beverage Group effects decreasing with increasing weekly alcohol consumption. Standard error confidence bands for ITI startle potentiation point estimates are displayed in gray.

Right Panel: Mean ITI startle potentiation scores are displayed by Beverage Group and Negative Emotionality. The Beverage Group $\times$ Negative Emotionality interaction was significant $(\mathrm{p}=.037)$, with Beverage Group effects increasing with increasing Negative Emotionality. Standard error confidence bands for ITI startle potentiation point estimates are displayed in gray. 


\section{Table 1}

Demographics, Personality, and Alcohol Use Individual Differences by Beverage Group.

\begin{tabular}{llll} 
Measure & Placebo & Alcohol & p-value \\
\hline $\mathrm{N}$ & 59 & 61 & \\
N Female & 29 & 30 & \\
Age (years) & $22.3(2.4)$ & $22.2(2.2)$ & .798 \\
Alcohol Use & & & \\
$\quad$ Frequency (occasions/week) & $1.8(1.3)$ & $2.2(1.7)$ & .136 \\
$\quad$ Quantity (drinks/occasion) & $4.1(1.9)$ & $4.7(2.7)$ & .114 \\
Alcohol Problems & & & \\
$\quad$ SMAST & $0.6(0.9)$ & $0.7(1.1)$ & .608 \\
$\quad$ YAAPS (past year) & $5.5(3.2)$ & $5.3(2.8)$ & .656 \\
Multidimensional Personality Questionnaire & & \\
$\quad$ Positive Emotionality & $77.2(14.3)$ & $76.6(13.9)$ & .812 \\
$\quad$ Negative Emotionality & $33.0(15.4)$ & $34.7(12.0)$ & .503 \\
Constraint & $73.1(12.5)$ & $71.8(12.0)$ & .558 \\
Shock Tolerance Threshold & $12.8(5.5)$ & $15.4(6.2)$ & $.014 *$ \\
\hline
\end{tabular}

NOTES: Table contains group means with standard deviations in parentheses unless otherwise indicated. No significant differences across Beverage Groups were observed for any of these variables.

YAAPS: Young Adult Alcohol Problems Scale past year problems

SMAST: Short Michigan Alcohol Screening Test

p $\leq .05$ 